\title{
Central Environmental Supervisors and Departure Audits of Outgoing Local Government Officials' Environmental Accountability: An Analysis Based on Game Theory
}

\author{
Rubing Liu', Yuyu Zhang', Teng Lin ${ }^{1}$, * \\ ${ }^{1}$ School of Accounting/Audit Governnance and Risk Control Research Center, Guangdong University of Foreign Studies, Guangzhou, China \\ ${ }^{2}$ School of Accountancy, Queensland University of Technology, Brisbane, Australia
}

Email address:

rbliu@gdufs.edu.cn (Rubing Liu), yuyu.zhang@qut.edu.au (Yuyu Zhang), linpt@gdufs.edu.cn (Teng Lin)

${ }^{*}$ Corresponding author

To cite this article:

Rubing Liu, Yuyu Zhang, Teng Lin. Central Environmental Supervisors and Departure Audits of Outgoing Local Government Officials' Environmental Accountability: An Analysis Based on Game Theory. Journal of Finance and Accounting. Vol. 8, No. 3, 2020 , pp. $115-124$. doi: $10.11648 /$ j.jfa.20200803.12

Received: April 1, 2020; Accepted: April 23, 2020; Published: May 14, 2020

\begin{abstract}
The establishment of central environmental supervision system (CESS) and the departure audits of outgoing local government officials are major environmental initiatives established by the Chinese government during the 18th National Congress of the Communist Party of China in 2012. Their aim is to separate the different environmental responsibilities of the local and central governments. In just one year, central environmental supervisors inspected 30 provinces' and cities' environmental performance and punished many local officials for their failures to fulfil their environmental responsibility as part of a national pollution crackdown. Inspired by the significant and profound effects of the environmental audits, we construct a tripartite game model involving the central auditors, environmental whistle-blowers and local government officials. We show that local government officials are more likely to act responsibly and that auditors adopt more detailed auditing procedures due to the involvement of whistle-blowers. This suggests that the central environmental supervision system must be institutionalised, legalised, normalised and focus on protections for whistle-blowers. Environmental audits are useful for focusing on departing officials' accountability for environmental protection. We urge the government to strengthen the transparency of audit and to distribute environmental audit information on social media.
\end{abstract}

Keywords: Environmental Audit, Environmental Responsibility, Environmental Whistle-blowing, Whistle-blower Protection System, Cooperative Governance, Tripartite Game Analysis

\section{Introduction}

'Lucid waters and lush mountains are the most valuable' was the slogan advocated by the 18th National Congress of the Communist Party of China, during which the Chinese central government placed great importance on the construction of a healthy environmental system [1]. In 2013, the Central Committee of Communist Party of China conducted highly visible environmental audits of departing leading government officials' efficacy in protecting natural resources. In 2015, audits were performed in the provinces of Hunan, Hebei, Inner Mongolia and Shanxi. The first experimental areas were in northern China, where heavy pollution is a serious problem. After two years of experimental audits, the State Administration of China issued the 'Regulation of Natural Resources Auditing of departing Leading Officials (Trial)' in November 2017, which mandates that environmental audits of outgoing officials be fully implemented by 2018 .

However, maintaining a healthy environment requires coordination by multiple agents. One cannot rely solely on central audits of departing officials' environmental performance [2]. Residents should exert legitimate power over environmental governance. The National Environmental Bureau, Provincial Environmental Bureau, municipal-level environmental monitoring detachments, county-level environmental monitoring brigades and six regional environmental centres located in different areas have all set 
up supervision branches where residents can report environmental breaches. Because residents are local, they can directly access environmental information and monitor the local government's environmental behaviour. A healthy environment is critical for residents, so they are very enthusiastic about participating in the protection of their environment. Therefore, an environmental breach reporting system encourages residents to participate in supervising the local government's environmental performance [3]. Doing this opens channels for local governance, forming an indispensable component of the environmental supervision system. It is also an effective way for the central government to reduce supervision costs and raise supervision efficiency.

China established an environmental breach reporting system many years ago. However, the drawbacks in the design of the system and the lack of trust by local communities hindered the functioning of the whistleblowing system. Since at least 2002, China has had an environmental supervision system operating at all levels, including the central, provincial, municipal and county levels $[4,5]$. In that system, environmental supervisors focused on enterprises and neglected the responsibility assumed by local governments in environmental governance [6]. Institutional reform was needed to strengthen the system's oversight over local government's environmental responsibility. Therefore, the 'Environmental Protection Supervision Rule (Trial)' was proposed in 2015, establishing an effective monitoring mechanism for environmental protection that provides supervisors the power to track whether local government officials are following the stringent requirements. Since the launch of the trial program in December 2015, the central environmental supervision system (CESS) has implemented the trial regulation in thirty-one provinces, including autonomous regions and municipalities across the country. Due to the resolve of the central government and residents' trust in the supervision system, the central environmental supervisors have received many reports of environmental violations from the public. During the first period of implementation, the supervisors received and acted on nearly one hundred and thirty-five thousand environmental breach reports (www.people.com.cn, $2017^{1}$ ). The central environmental supervisors have achieved remarkable results. One report states that 'The central environmental supervisors have settled some reporting cases overnight. Their efficiency is beyond expectation because some cases remained unsolved for many years before the introduction of the 2015 trial regulation, ${ }^{2}$.

The purpose of appointing central environmental supervisors and performing audits of departing officials' environmental performance is to increase local governments'

\footnotetext{
1 'The central environmental protection supervision has covered 31 provinces and will continue audit next year' as reported in www.people.cn (Dated 29/12/2017). See the details in http://politics.people.com.cn/n1/2017/1229/c1001-29734963.html.

2 'The central environmental protection inspector was strongly embraced by the public'. See www.qstheory.cn (Dated 24/8/2017) and more details in http://www.qstheory.cn/zoology/2017-08/24/c_1121537496.htm.
}

commitment to environmental protection. We examine the role of local officials, auditors and environmental whistle-blowers in a tripartite game model of the current institutional arrangement. We apply the model to explain the relation between CESS and environmental auditing. First, central supervisors' strong involvement in local audits shows the central government's determination to protect the environment and to hold local governments accountable for environmental damage. Second, the introduction of the whistle-blower protection system encourages residents to assist central supervisors in monitoring local government environmental responsibility. Our model sheds light on the efficiency and effectiveness of China's current environmental policies, which is important as China uses nearly $40 \%$ of global resources in manufacture industries. China's environmental policies influence local governments' environmental performance and have profound impacts on the rest of the world. Indeed, the recent enforcement of environmental protections in China is changing the global supply chains [7].

\section{Background and Literature Review}

On 4 January 2016, the Central Environmental Supervision Committee (CESC) was officially introduced in Chinese media and titled 'Huan Bao Qin Chai'. Huan Bao means environmental protection and Qin Chai refers to delegates appointed by the Chinese central government, which has ultimate environmental supervision power over local governments. The CESC, jointly formed by the Ministry of Environmental Protection and the Communist Party's Commission for Discipline Inspection (CCDI), is a central environmental agency supervising the local implementation of environmental tasks set by the Communist Party's Central Committee and the State Council. The CESC is not a toothless tiger because their supervision results are an important part of local governmental officials' performance evaluations and hence political promotion. Environmental supervision is implemented at the various levels of provinces, autonomous regions, municipalities and related governmental departments. The establishment of CESC is a major institutional step for the Central Communist Party and the State Council in promoting the construction of an ecologically friendly civilisation and reinforcing environmental protections. Xi Jinping, the China's president, places great importance on the work of environmental supervisors and supports important measures for promoting the construction of an ecologically friendly civilisation. Xi has strengthened the environmental protection requirements of the party and of the government and emphasized governmental officials' environmental accountability alongside economic achievements.

\subsection{The Role of Central Environmental Supervisors}

The appointment of central environmental supervisors was initiated by the Chinese Ministry of Ecology and Environment and empowered by the Communist Party's 
central committee. CESC's key responsibility include (1) supervising local Communist Party Committees and the implementation of the national environmental protection policy, (2) solving environmental problems, (3) monitoring officials' protection of the environment, (4) encouraging local governments to help in the construction of an ecologically friendly civilisation and (5) promoting green development. CESC focuses on problematic areas including (1) areas of high concern to the central government, (2) areas that provoke strong public condemnation from locals, (3) areas with strongly negative social impacts, (4) deteriorating regional watersheds, (5) inappropriate behaviour by local party committee members and government administrators in handling environmental protection issues and (6) environmental regulation compliance issues. Prior to the establishment of CESC, many environmental violations were identified, reported and assigned to different levels or departments of local government to resolve. However, environmental cases were handled within the circle of local government and lacked proper supervision from the central government. The dominance of local leadership, the complicated relationships between different groups and opaque local policies in place to protect local interest groups at the expense of the environment were roadblocks to solving environmental problems. Without powerful supervision, many environmental problems remained unsolved, as reported by an environmental reporter who investigated the causes of inefficient environmental protection.

During 2016 and 2017, the CESC deployed to thirty-one provinces and held more than fifteen thousand people accountable. When the environmental supervisors are stationed in an area, the public can report any environmental issues directly to the CESC via phone or email. Once the reports are verified and accepted, they are transferred to the local department for investigation. The local department is required to provide timely feedback that is accessible to the public. Reports are randomly selected for cross-examination by other supervisors. Some of the letters and visits are reviewed to reverify them. Local governments and related departments are held responsible if they fail to conduct reliable investigations and provide consistent feedback. According to the statistics provided by the $\mathrm{CESC}^{3}$, eight local branches of the CESC received 44,134 environmental breach reports from the public as of 4 September 2017. Of them, 32,277 reports were verified and accepted for investigation. After consolidating repeated reports, 29,189 reports remained and were transferred for further investigation. In the end, 18,565 reports were thoroughly examined, and 5,625 reports were filed for legal punishments with a total penalty of RMB280 million.

\subsection{Whistle-blower Protection System in China}

Researchers have long noticed the important role of whistle-blowers. In 1983, the American scholar Malin pointed out that a whistle-blower protection system should be established to

\footnotetext{
${ }^{3}$ Source: http://politics.people.com.cn/n1/2018/0108/c1001-29750061.html
}

protect whistle-blowers from harassment [8]. This argument was supported by Dworkin and Callahan [9]. Murdockbelieved that companies' internal whistle-blower systems help enterprises to take measures at an early stage and prevent problems from deteriorating [10]. Westman demonstrated the importance of the whistle-blower protection clauses in the Sarbanes-Oxley Act [11]. Sawyer et al. analysed the significance of establishing a whistle-blower protection system from the perspective of organisational legitimacy [12]. Cordis and Lambert found that whistle-blower protection systems deter corporate fraud [13]. The term 'environmental fraud' in this paper refers to local governments' falsification of environmental performance by hiding key information, preparing inaccurate reports and other means.

There is a large body of research on China's whistle-blower protection systems. Lai et al. argued that it is a country's responsibility to establish a whistle-blower protection system [14]. Wu believed that a reward and reporting system is a vital information channel for society which plays important roles both in information production and in deterrence [15]. Qian et al. showed that whistle-blower protections can change drug regulation from institutional supervision to public supervision, reducing labour and material costs for regulatory agencies [16]. In discussing food safety, Yin et al. and Che et al. showed the importance of a whistle-blower protection system for China's food industry $[17,18]$. Luan et al. found that companies with good whistle-blower protection systems had lower costs of external auditing and better deterrence of false disclosure of internal controls [19]. Zhang showed that protecting and rewarding whistle-blowers is an indispensable part of building an environmental governance pattern [20].

\subsection{CESC and Environmental Audits in China}

Conducting environmental audits of departing government officials' management of natural resources is a new measure taken by the Chinese central government in recent years. We thoroughly examine the literature evaluating such governance measures. Liu claimed that the CESC has significantly enhanced the influence, intensity and effectiveness of environmental protection initiatives [21]. Ge et al. asserted that the CESC is helpful in promoting a long-term environmental protection mechanism for local governments [22]. Li studied the mailbox services and other communication channels used by the CESC for whistle-blowers and showed that whistle-blowers are of great help in bringing specific environmental issues to the CESC's attention during local visits [23]. Cai and $\mathrm{Bi}$ analysed the motivation, theoretical basis and theoretical issues for departing officials in terms of environmental protection [24]. Li and Yin also studied the theoretical background and basic methods for environmental audits of departing officials [25]. Liu and Sun discussed the subject, object and expected users of the audit reports of departing officials' environmental achievements [26].

The experimental project for the environmental audit of departing officials was officially launched in November 2015. Chen et al., Wang et al., Qin et al. and Zhou et al. [27-30] analysed the problems in the experimental process and 
proposed recommendations for improving the project. Using an evolutionary game theory model, Liu and Wang found that environmental audits can strengthen the environmental responsibility of local governments, helping to solve failures in environmental governance [31]. The literature has fully demonstrated the importance of whistle-blower protection systems. Many developed countries have established advanced whistle-blower protection systems. However, China must make progress in protecting whistle-blowers' safety. One role of the CESC is to open channels for local environmental whistle-blowers to communicate directly and safely with supervisors. A well-functioning protection and inspection system encourages the timely detection of environmental violations. In addition, the CESC supervises environmental audit procedures that are strictly followed in the detected areas. Therefore, the CESC, whistle-blowers and auditors should act cooperatively in performing environmental audits of departing officials. To the best of our knowledge, there is no study that explains the mechanisms of cooperative governance in environmental audits. External auditors appreciate the importance of corporate environmental performance as suggested in a recent study by $\mathrm{Du}$, Jian, Zeng and Chang [32]. The environmental audit process itself is a game between the CESC, environmental auditors and local governments. The intervention of the CESC affects the behavioural choices of auditors and departing officials. Therefore, the game theory analysis method is appropriate for explaining the interactions between the different parties.

\section{Game model Construction}

\subsection{Theoretical Analysis}

The environment is a special public product that cannot be substituted by something else. When the distance between the central government and local environment is great, responsibility for the local environmental is directly borne by the local government. However, the local government has different political targets which may conflict with the central government's long-term environmental plan in the short-term. For example, local government officials usually have a tenure of three to five years, but the effects of environmental investments are long-term, often more than five years. Before the environmental reforms, local promotion was primarily based on economic performance. Therefore, local officials were motivated to develop the economy at the expense of the local environment if these two goals were in conflict in the short term. Without an effective audit of their environmental management, departing officials were motivated to disclose inaccurate information or to conduct environmental fraud for their own political interests [33]. Doing so helped local officials get promoted to higher positions due to their economic achievements [34, 35].

The local environment has a direct influence on the quality of life of residents. This means that residents are sensitive to unfavourable changes resulting from bad environment governance and so are incentivised to act as environmental whistle-blowers. Before the environmental reforms and the appointment of central environmental supervisors, information reported by residents did not reach the environmental authority and so could not be effectively used. Residents were also concerned about acting as whistle-blowers because of potential conflicts with the local government officials and interest groups. Because of the fear of revenge, whistle-blowers need a strong protection system. The CESC plays a key role in unblocking the channel for public informants to deter the local government from environmental fraud by protecting whistle-blowers from suppression and personal harassment.

When environmental auditors audit departing officials, they can adopt different audit procedures according to the job requirement. However, auditors may have difficulties accessing authentic information sources due to information asymmetries and this can lead to audit failures. Audit failures affect the reputation of the assigned auditor and of the whole government auditing agency. This leads to a loss in residents' and whistle-blowers' trust and discourages whistleblowing activity, which in turn makes it harder for the auditor to access information. In short, the quality of audit results affects whistle-blowers' reporting. The set-up of the CESC system directly affects the behavioural choices of potential whistle-blowers. An effective system encourages informants to report matter quickly and accurately. Information provided by whistle-blowers has a profound impact on the behavioural choices of local officials and auditors. Therefore, environmental audits are a game between the departing officials, auditors and whistle-blowers.

\subsection{Model Assumptions}

To construct the game model, we make the following assumptions.

Hypothesis 1: There are three players in the game: the local government official, auditor and informant (potential whistle-blower). We assume that each participant is a rational economic identity with risk neutral preferences. Everyone makes reasonable strategic decisions based on the actions of other game participants to maximize utility.

Hypothesis 2: The strategic performance of the local officials is defined as (Good local officials, Bad local officials\}. Local officials who have implemented central environmental protection policies and performed well in environmental protection are called good local officials. Local officials who have not done this are called bad local officials. Bad local officials have strong motives to commit environmental fraud due to various political interests such as promotion.

Hypothesis 3: The auditor's strategic policy is defined as \{complex audit, simple audit\}. A detailed and tailor-made audit procedure is called a complex audit. Otherwise, it is a simple audit. Complex audits reduce the risk of audit failures but cost more. Simple audits cost less but have a higher risk of audit failure.

Hypothesis 4: The local informant's strategic choice is defined as \{whistle-blower, non-whistle-blower\}. If an 
informant reports a violation of environmental regulations, environmental fraud or something similar, we call the informant a whistle-blower; otherwise, he is a non-whistle-blower. Reporting to the CESC is an appropriate action when the local government does not take measures to deal with the problem. It can be worse when officials collaborate with local interest groups in the matter. However, if the informant chooses to become a whistle-blower, he may become a potential victim of the local government's revenge without a protection system. Therefore, there are costs associated with being a whistle-blower. We analyse the whistle-blowing decision based on a cost-benefit calculation of the trade-off between being a whistle-blower and being a non-whistle-blower.

\subsection{Game Model Construction}

Based on the theoretical analysis and assumptions, the game process model for constructing the strategic choices of the local official, auditor and whistle-blower is shown in Figure 1.

\subsubsection{Game Process Analysis}

First, local officials are divided into two types: good local officials and bad local officials. We denote $\beta$ as the probability that auditors judge a good local official as a 'good official'. It is possible for the auditor to implement a complex audit or a simple audit based on different type of clients. This is respectively based on the policy combinations (1) and (2) in Figure 1. When a bad local official claims to be 'good official', the probability that the auditor judges them as a 'bad official' is $(1-\beta)$. At this time, if the auditor implements a complex audit, the probability she detects a bad official is denoted by $\lambda_{1}$, as shown on the strategy set (3) in Figure 1. The probability that the auditor fails to detect is $1-\lambda_{1}$. This is then divided into two scenarios depending on the informant's choice of whether to be a whistle-blower. Upon receiving the whistle-blower's information, the local official has two choices, suppress or not suppress, as shown on (4), (5) and (6) in Figure 1. Similarly, if the auditor implements a simple audit, the probability that she detects a bad official is denoted as $\lambda_{2}$, which is shown on (7) in Figure 1. The probability of not detecting a bad official is $1-\lambda_{2}$. This is then divided into two scenarios depending on the informant's choice of whether to be a whistle-blower. Upon receiving the informant's information, the local official has two choices, suppress or not suppress, as shown on (8, (9) and (10).

\subsubsection{Analysis of the Income of All Parties in the Game}

According to the game model shown in Figure 1, we classify two scenarios (with and without CESS) to discuss the benefits in the game for the three participants (local official, auditor and whistle-blower). The benefits in the two scenarios are shown in Tables 1 and 2. The definitions of the symbols are in Table 3.

\section{The Game Model Analysis}

\subsection{Scenario 1: There Is No CESS}

As is shown in Table 1, under such hypothetical circumstances, the benefit to the local official of suppressing the whistle-blower is $E_{1}-E_{2}-E_{3}+E_{4}$, while the benefit of not suppressing the whistle-blower is $E_{1}-E_{2}-E_{3}$. It is obvious that $E_{1}-E_{2}-E_{3}+E_{4}>E_{1}-E_{2}-E_{3}$; therefore, the dominant strategy of the local official is to suppress. If the official is suppressing, the informant's benefit from whistleblowing is $V_{1}-V_{2}+V_{3}$ and her benefit from not whistleblowing is $V_{1}$. When the tangible or intangible incentive $V_{3}$ obtained by whistleblowing is greater than the loss of suffering suppression $V_{2}$, the informant chooses whistleblowing. In this case, \{suppression, whistleblowing is the Nash equilibrium of the game between the local official and the informant; if $V_{3}<V_{2}$, the informant chooses not to be a whistle-blower and \{suppression, non-whistleblowing is the Nash equilibrium of the game between the local official and the informant.

Due to information asymmetries, the auditor cannot accurately judge whether the local official acts diligently and can only decide to conduct a complex rather than a simple audit based on his or her judgment.

i. When $V_{3}>V_{2}$, the local official suppresses and the informant reports. Anticipating this, the auditor's benefit to a complex audit is $\beta\left(S_{1}-C\right)+(1-\beta) \lambda_{1}\left(S_{1}-C\right)+$ $(1-\beta)\left(1-\lambda_{1}\right)\left(S_{1}-C-S_{2}\right)$. The benefit of a simple audit is $\quad \beta S_{1}+(1-\beta) \lambda_{2} S_{1}+(1-\beta)\left(1-\lambda_{2}\right)\left(S_{1}-\right.$ $\left.S_{2}\right)$. Subtracting the second equation from the first results in $(1-\beta) S_{2}\left(\lambda_{1}-\lambda_{2}\right)-C$. Let $\lambda_{1}-\lambda_{2}=\lambda^{\prime}$.

a. When $\beta<\left(S_{2} \lambda^{\prime}-C\right) / S_{2} \lambda^{\prime}$, the auditor performs a complex audit. Then, the benefit to a bad official of claiming to be a good official is $\lambda_{1}\left(E_{1}-E_{2}-E_{3}\right)+\left(1-\lambda_{1}\right)\left(E_{1}-\right.$ $\left.E_{2}-E_{3}+E_{4}\right)$ and the benefit of claiming to be a bad official is $E_{1}-E_{2}$. Subtracting the second equation from the first results in $\left(1-\lambda_{1}\right) E_{4}-E_{3}$.

Conclusion 1: When $V_{3}>V_{2}$ and $E_{4}>E_{3} /\left(1-\lambda_{1}\right)$, the auditor performs a complex audit and the bad official claims to be a good official.

b. When $\beta>\left(S_{2} \lambda^{\prime}-C\right) / S_{2} \lambda^{\prime}$, the auditor performs a simple audit. In this case, if the bad official claims to be a good official, she receives the benefit $\lambda_{2}\left(E_{1}-E_{2}-E_{3}\right)+$ $\left(1-\lambda_{2}\right)\left(E_{1}-E_{2}-E_{3}+E_{4}\right)$. The benefit of claiming to be a bad official is $E_{1}-E_{2}$. Subtracting the second equation from the first results in $\left(1-\lambda_{2}\right) E_{4}-E_{3}$.

Conclusion 2: When $V_{3}>V_{2}$ and $E_{4}>E_{3} /\left(1-\lambda_{2}\right)$, the auditor performs a simple audit and the bad official claims to be a good official.

ii. When $V_{3}<V_{2}$, the local official chooses suppression and the informant chooses to not be a whistle-blower. At this point, the benefit to the auditor of choosing a complex audit is $\beta\left(S_{1}-C\right)+(1-\beta) \lambda_{1}\left(S_{1}-C\right)+(1-\beta)\left(1-\lambda_{1}\right)\left(S_{1}-\right.$ $\left.C-\varepsilon S_{2}\right)$ and the benefit of selecting a simple audit is $\beta S_{1}+(1-\beta) \lambda_{2} S_{1}+(1-\beta)\left(1-\lambda_{2}\right)\left(S_{1}-\varepsilon S_{2}\right)$. The difference between the two is $(1-\beta) \varepsilon S_{2}\left(\lambda_{1}-\lambda_{2}\right)-C$. Let $\lambda_{1}-\lambda_{2}=\lambda^{\prime}$. If $(1-\beta) \varepsilon S_{2}\left(\lambda_{1}-\lambda_{2}\right)-C>0$, then when $\beta<\left(\varepsilon S_{2} \lambda^{\prime}-C\right) / \varepsilon S_{2} \lambda^{\prime}$, the auditor chooses a complex audit; otherwise, she chooses a simple audit.

a. When $\beta<\left(\varepsilon S_{2} \lambda^{\prime}-C\right) / \varepsilon S_{2} \lambda^{\prime}$, the auditor chooses a complex audit. In this case, if the bad official claims to be a good official, his benefit is $\lambda_{1}\left(E_{1}-E_{2}-E_{3}\right)+(1-$ 
$\left.\lambda_{1}\right)\left(E_{1}-\varepsilon E_{2}-\varepsilon E_{3}\right)$. The benefit to him of admitting being a bad official is $E_{1}-E_{2}$. The difference is $\varepsilon\left(\lambda_{1}-1\right)\left(E_{2}+\right.$ $\left.E_{3}\right)+\left(-\lambda_{1} E_{2}-\lambda_{1} E_{3}+E_{2}\right)$.

Conclusion 3: When $V_{3}<V_{2}$ and $\varepsilon>\left[\left(1-\lambda_{1}\right) E_{2}-\right.$ $\left.\lambda_{1} E_{3}\right] /\left[\left(1-\lambda_{1}\right)\left(E_{2}+E_{3}\right)\right]$, the auditor chooses a complex audit and the bad official claims to be a good official. b. When $\beta>\left(\varepsilon S_{2} \lambda^{\prime}-C\right) / \varepsilon S_{2} \lambda^{\prime}$, the auditor chooses a simple audit. Then, the benefit to a bad official of claiming to be a good official is $\lambda_{2}\left(E_{1}-E_{2}-E_{3}\right)+\left(1-\lambda_{2}\right)\left(E_{1}-\right.$ $\left.\varepsilon E_{2}-\varepsilon E_{3}\right)$. The benefit of admitting being a bad official is $E_{1}-E_{2}$. The difference between these two equations is $\varepsilon\left(\lambda_{2}-1\right)\left(E_{2}+E_{3}\right)+\left(-\lambda_{2} E_{2}-\lambda_{2} E_{3}+E_{2}\right)$.

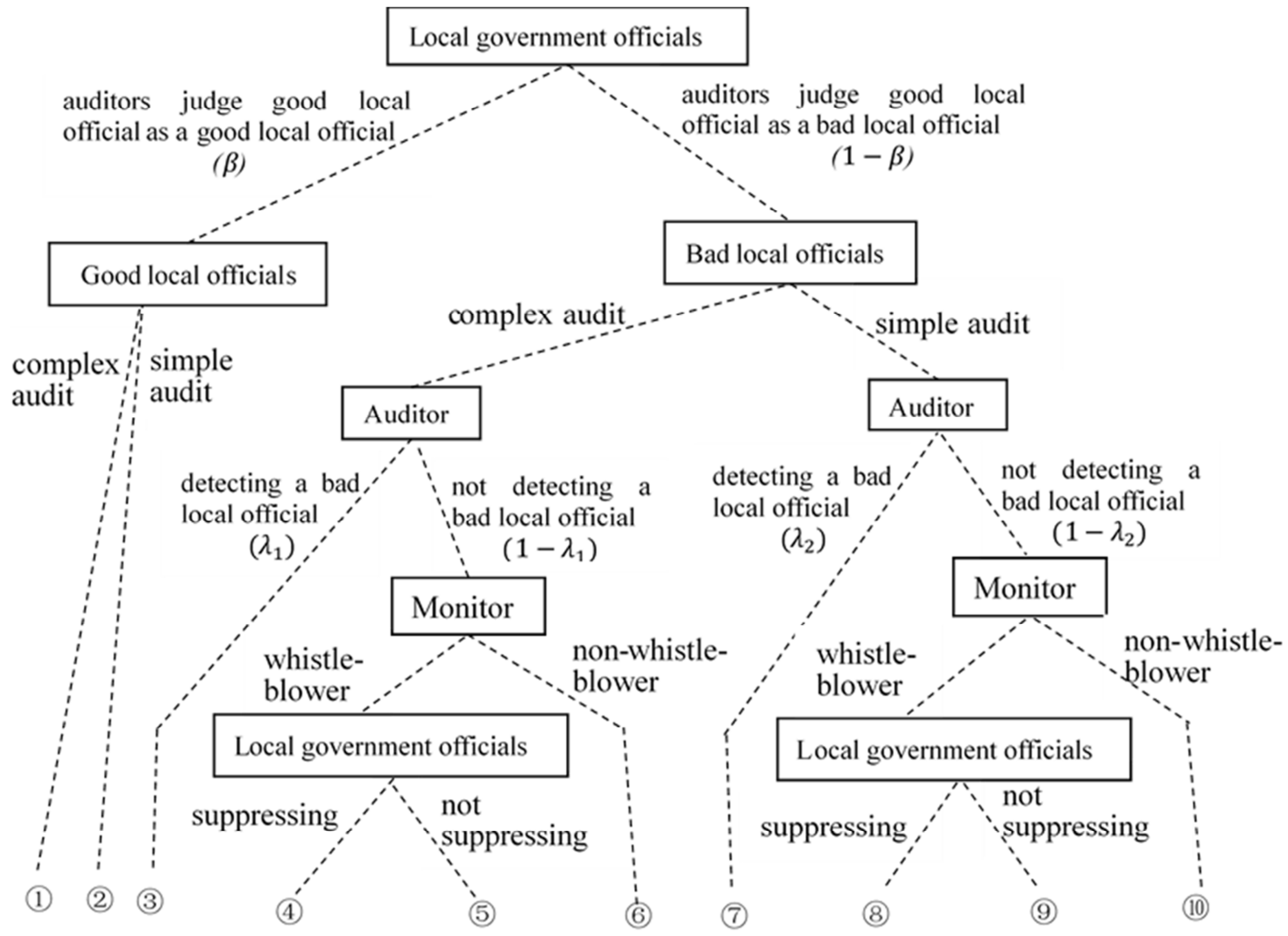

Figure 1. Decision tree.

Table 1. Analysis of the Tripartite Game Benefits without CESS.

\begin{tabular}{llll}
\hline Strategic combination & Local government official & Auditor & Whistle-blower \\
\hline (1) & $E_{1}$ & $S_{1}-C$ & $V_{1}$ \\
(2) & $E_{1}$ & $S_{1}$ & $V_{1}$ \\
(3) & $E_{1}-E_{2}-E_{3}$ & $S_{1}-C$ & $V_{1}$ \\
(4) & $E_{1}-E_{2}-E_{3}+E_{4}$ & $S_{1}-C-S_{2}$ & $V_{1}-V_{2}+V_{3}$ \\
(5) & $E_{1}-E_{2}-E_{3}$ & $S_{1}-C-S_{2}$ & $V_{1}+V_{3}$ \\
(6) & $E_{1}-\varepsilon E_{2}-\varepsilon E_{3}$ & $S_{1}-C-\varepsilon S_{2}$ & $V_{1}$ \\
(7) & $E_{1}-E_{2}-E_{3}$ & $S_{1}$ & $V_{1}$ \\
(8) & $E_{1}-E_{2}-E_{3}+E_{4}$ & $S_{1}-S_{2}$ & $V_{1}-V_{2}+V_{3}$ \\
(9) & $E_{1}-E_{2}-E_{3}$ & $S_{1}-S_{2}$ & $V_{1}+V_{3}$ \\
(1) & $E_{1}-\varepsilon E_{2}-\varepsilon E_{3}$ & $S_{1}-\varepsilon S_{2}$ & $V_{1}$ \\
\hline
\end{tabular}

Table 2. Analysis of the Tripartite Game Benefits with CESS.

\begin{tabular}{llll}
\hline Strategic combination & Local government official & Auditor & Whistle-blower \\
\hline (1) & $E_{1}$ & $S_{1}-C$ & $V_{1}$ \\
(2) & $E_{1}$ & $S_{1}$ & $V_{1}$ \\
(3) & $E_{1}-E_{2}-E_{3}$ & $S_{1}-C$ & $V_{1}$ \\
(4) & $E_{1}-E_{2}-E_{3}+\mu E_{4}-(1-\mu) V_{4}$ & $S_{1}-C-S_{2}$ & $V_{1}-\mu V_{2}+V_{3}+(1-\mu) V_{4}$ \\
(5) & $E_{1}-E_{2}-E_{3}$ & $S_{1}-C-S_{2}$ & $V_{1}+V_{3}$ \\
(6) & $E_{1}-\varepsilon E_{2}-\varepsilon E_{3}$ & $S_{1}-C-\varepsilon S_{2}$ & $V_{1}$ \\
(7) & $E_{1}-E_{2}-E_{3}$ & $S_{1}$ & $V_{1}$ \\
(8) & $E_{1}-E_{2}-E_{3}+\mu E_{4}-(1-\mu) V_{4}$ & $S_{1}-S_{2}$ & $V_{1}-\mu V_{2}+V_{3}+(1-\mu) V_{4}$ \\
(9) & $E_{1}-E_{2}-E_{3}$ & $S_{1}-S_{2}$ & $V_{1}+V_{3}$ \\
(1) & $E_{1}-\varepsilon E_{2}-\varepsilon E_{3}$ & $S_{1}-\varepsilon S_{2}$ & $V_{1}$ \\
\hline
\end{tabular}


Table 3. Definition of Symbols.

\begin{tabular}{ll}
\hline$E_{1}$ & The benefits to good officials under normal conditions. \\
$E_{2}$ & The cost to local officials when the local officials is identified as a bad official by the auditor. \\
$E_{3}$ & Reputation loss caused by local leader's 'unfaithful behaviour'. \\
$E_{4}$ & Improvement in local official's utility from suppressing whistle-blower (for example, by suppressing the information reported by the \\
$\varepsilon$ & whistle-blower and reducing the number of whistle-blowers). \\
$\mu$ & The probability of detecting bad officials. \\
$V_{1}$ & The probability a local official successfully suppresses whistleblowing under CESS. \\
$V_{2}$ & Wnvironmental benefits to potential whistle-blower under normal conditions. \\
$V_{3}$ & Whistle-blower's personal loss due to reporting the environmental breach. \\
$V_{4}$ & Whistle-blower's rewards from CESS. \\
$S_{1}$ & The income of the auditor for providing service. \\
$C$ & The additional costs of conducting a complex rather than a simple audit. \\
$S_{2}$ & Auditor's loss due to audit failure. \\
\hline
\end{tabular}

Conclusion 4: When $V_{3}<V_{2}$ and $\varepsilon>\left[\left(1-\lambda_{2}\right) E_{2}-\right.$ $\left.\lambda_{2} E_{3}\right] /\left[\left(1-\lambda_{2}\right)\left(E_{2}+E_{3}\right)\right]$, the auditor chooses a simple audit and the bad official claims to be a good official.

\subsection{Scenario 2: There Is a CESS}

Similar to the Scenario 1 analysis, it is known from Table 2 that when there is a CESS, the benefit to the local official of suppressing the whistle-blower is $E_{1}-E_{2}-E_{3}+\mu E_{4}-$ $(1-\mu) V_{4}$ and the benefit to the official of not suppressing the whistle-blower is $E_{1}-E_{2}-E_{3}$. It is obvious that when $\mu E_{4}>(1-\mu) V_{4}$, the local official suppresses the whistle-blower. If the local official suppresses the whistle-blower, the benefit of whistleblowing is $V_{1}-\mu V_{2}+$ $V_{3}+(1-\mu) V_{4}$. The benefit to not whistleblowing is $V_{1}$. Therefore, when $-\mu V_{2}+V_{3}+(1-\mu) V_{4}>0$, the informant chooses to be a whistle-blower; otherwise, the informant chooses to not be a whistle-blower. If the local official does not suppress, the benefit of whistleblowing is $V_{1}+V_{3}$ and the benefit of not whistleblowing is still $V_{1}$. In this case, the informant chooses to report. Therefore, the following conclusions can be drawn.

Conclusion 1: When $\mu>V_{4} /\left(E_{4}+V_{4}\right)$ and $\mu<\left(V_{3}+\right.$ $\left.V_{4}\right) /\left(V_{2}+V_{4}\right)$, \{suppression, whistleblowing\} is the Nash equilibrium of the game between the local official and the informant.

Conclusion 2: When $\mu>V_{4} /\left(E_{4}+V_{4}\right)$ and $\mu>\left(V_{3}+\right.$ $\left.V_{4}\right) /\left(V_{2}+V_{4}\right)$, \{suppression, non-whistleblowing\} is the Nash equilibrium of the game between the local official and the informant.

Conclusion 3: When $\mu<V_{4} /\left(E_{4}+V_{4}\right)$, \{no suppression, non-whistleblowing $\}$ is the Nash equilibrium of the game between the local official and the informant.

Similarly, due to information asymmetries, the auditor cannot accurately determine the official's conduct. She can only decide whether to adopt a complex auditing procedure or a simple auditing procedure according to prior experience. Hence, the analysis of the game process between the local official, auditor and whistle-blower is as follows.

i. When $\mu>V_{4} /\left(E_{4}+V_{4}\right)$ and $\mu<\left(V_{3}+V_{4}\right) /\left(V_{2}+V_{4}\right)$, \{suppression, whistleblowing\} is the Nash equilibrium of the game between the local official and the informant.

In this case, the benefit to the auditor of choosing a complex audit is $\beta\left(S_{1}-C\right)+(1-\beta) \lambda_{1}\left(S_{1}-C\right)+$ $(1-\beta)\left(1-\lambda_{1}\right)\left(S_{1}-C-S_{2}\right)$. The benefit of selecting a simple audit is $\beta S_{1}+(1-\beta) \lambda_{2} S_{1}+(1-\beta)(1-$
$\left.\lambda_{2}\right)\left(S_{1}-S_{2}\right)$. The difference between these two equations is $(1-\beta) S_{2}\left(\lambda_{1}-\lambda_{2}\right)-C$. Let $\lambda_{1}-\lambda_{2}=\lambda^{\prime}$. We can conclude that if $\beta<\left(S_{2} \lambda^{\prime}-C\right) / S_{2} \lambda^{\prime}$, the auditor will choose a complex audit; otherwise, she selects a simple audit.

a. When $\beta<\left(S_{2} \lambda^{\prime}-C\right) / S_{2} \lambda^{\prime}$, the auditor chooses a complex audit. In this case, the benefit to a bad official of claiming to be a good official is $\lambda_{1}\left(E_{1}-E_{2}-E_{3}\right)+$ $\left.\left(1-\lambda_{1}\right)\left[\left(E_{1}-E_{2}-E_{3}+\mu E_{4}-(1-\mu) V_{4}\right)\right]\right]$. The benefit of admitting to being a bad official is $E_{1}-E_{2}$. The difference between these two equations is $\mu\left(1-\lambda_{1}\right)\left(E_{4}+\right.$ $\left.V_{4}\right)-\left(E_{4}+V_{4}-\lambda_{1} V_{4}\right)$.

Conclusion 1: When $\mu>V_{4} /\left(E_{4}+V_{4}\right), \quad \mu<\left(V_{3}+\right.$ $\left.V_{4}\right) /\left(V_{2}+V_{4}\right)$ and $\mu>\left[E_{3}+\left(1-\lambda_{1}\right) V_{4}\right] /\left[\left(1-\lambda_{1}\right)\left(E_{4}+\right.\right.$ $\left.V_{4}\right)$ ], the auditor chooses a complex audit and the bad official pretends to be a good official.

b. When $\beta>\frac{S_{2} \lambda^{\prime}-C}{S_{2} \lambda^{\prime}}$, the auditor chooses a simple audit. In this case, the benefit to a bad official of claiming to be good official is $\lambda_{2}\left(E_{1}-E_{2}-E_{3}\right)+\left(1-\lambda_{2}\right)\left[\left(E_{1}-E_{2}-\right.\right.$ $\left.\left.E_{3}+\mu E_{4}-(1-\mu) V_{4}\right)\right]$. The benefit of admitting to being a bad official is $E_{1}-E_{2}$. The difference is $\mu\left(1-\lambda_{2}\right)\left(E_{4}+\right.$ $\left.V_{4}\right)-\left(E_{4}+V_{4}-\lambda_{2} V_{4}\right)$.

Conclusion 2: When $\mu>V_{4} /\left(E_{4}+V_{4}\right), \quad \mu<\left(V_{3}+\right.$ $\left.V_{4}\right) /\left(V_{2}+V_{4}\right)$ and $\mu>\left[E_{3}+\left(1-\lambda_{2}\right) V_{4}\right] /\left[\left(1-\lambda_{2}\right)\left(E_{4}+\right.\right.$ $\left.\left.V_{4}\right)\right]$, the auditor chooses a complex audit and the bad official claims to be a good official.

ii. When $\mu>V_{4} /\left(E_{4}+V_{4}\right)$ and $\mu>\left(V_{3}+V_{4}\right) /\left(V_{2}+V_{4}\right)$, \{suppression, non- whistle-blowing\} is the Nash equilibrium of the game between the local official and the informant.

In this case, the benefit to the auditor of a complex audit is $\beta\left(S_{1}-C\right)+(1-\beta) \lambda_{1}\left(S_{1}-C\right)+(1-\beta)\left(1-\lambda_{1}\right)\left(S_{1}-\right.$ $\left.C-\varepsilon S_{2}\right)$. The benefit of a simple audit is $\beta S_{1}+(1-$ ק) $\lambda_{2} S_{1}+(1-\beta)\left(1-\lambda_{2}\right)\left(S_{1}-\varepsilon S_{2}\right)$. The difference between the two is $(1-\beta) \varepsilon S_{2}\left(\lambda_{1}-\lambda_{2}\right)-C$. Let $\lambda_{1}-\lambda_{2}=$ $\lambda^{\prime}$. When $\beta<\left(\varepsilon S_{2} \lambda^{\prime}-C\right) / \varepsilon S_{2} \lambda^{\prime}$, the auditor chooses a complex audit; otherwise, she chooses a simple audit.

a. When $\beta<\left(\varepsilon S_{2} \lambda^{\prime}-C\right) / \varepsilon S_{2} \lambda^{\prime}$, complex auditing is chosen. In this case, the benefit to a bad official of claiming to be a good official is $\lambda_{1}\left(E_{1}-E_{2}-E_{3}\right)+\left(1-\lambda_{1}\right)\left(E_{1}-\right.$ $\left.\varepsilon E_{2}-\varepsilon E_{3}\right)$. The benefit of confessing to be a bad official is $E_{1}-E_{2}$. The difference between these two is $\varepsilon\left(\lambda_{1}-1\right)\left(E_{2}+\right.$ $\left.E_{3}\right)+\left(-\lambda_{1} E_{2}-\lambda_{1} E_{3}+E_{2}\right)$.

Conclusion 3: When $\mu>V_{4} /\left(E_{4}+V_{4}\right), \mu>\left(V_{3}+\right.$ $\left.V_{4}\right) /\left(V_{2}+V_{4}\right) \quad$ and $\quad \varepsilon>\left[\left(1-\lambda_{1}\right) E_{2}-\lambda_{1} E_{3}\right] /[(1-$ $\left.\left.\lambda_{1}\right)\left(E_{2}+E_{3}\right)\right]$, the auditor chooses a complex audit and the 
bad official claims to be a good official.

b. When $\beta>\left(\varepsilon S_{2} \lambda^{\prime}-C\right) / \varepsilon S_{2} \lambda^{\prime}$, the auditor chooses a simple audit. In this case, the benefit to a bad official of claiming to be a good official is $\lambda_{2}\left(E_{1}-E_{2}-E_{3}\right)+(1-$ $\left.\lambda_{2}\right)\left(E_{1}-\varepsilon E_{2}-\varepsilon E_{3}\right)$. The benefit of admitting to be a bad official is $E_{1}-E_{2}$. The difference between the two is $\varepsilon\left(\lambda_{2}-1\right)\left(E_{2}+E_{3}\right)+\left(-\lambda_{2} E_{2}-\lambda_{2} E_{3}+E_{2}\right)$.

Conclusion 4: When $\mu>V_{4} /\left(E_{4}+V_{4}\right), \mu>\left(V_{3}+\right.$ $\left.V_{4}\right) /\left(V_{2}+V_{4}\right)$ and $\varepsilon>\left[\left(1-\lambda_{2}\right) E_{2}-\lambda_{2} E_{3}\right] /[(1-$

$\left.\left.\lambda_{2}\right)\left(E_{2}+E_{3}\right)\right]$, the auditor chooses a simple audit and the bad official claim to be a good official.

iii. When $\mu<V_{4} /\left(E_{4}+V_{4}\right)$, \{no suppression, non-whistleblowing $\}$ is the Nash equilibrium of the game between the local official and the informant.

In this case, the benefit to the auditor of a complex audit is $\beta\left(S_{1}-C\right)+(1-\beta) \lambda_{1}\left(S_{1}-C\right)+(1-\beta)\left(1-\lambda_{1}\right)\left(S_{1}-\right.$ $\left.C-S_{2}\right)$. The benefit of selecting a simple audit is $\beta S_{1}+$ $(1-\beta) \lambda_{2} S_{1}+(1-\beta)\left(1-\lambda_{2}\right)\left(S_{1}-S_{2}\right)$. The difference between the two equations is $(1-\beta) S_{2}\left(\lambda_{1}-\lambda_{2}\right)-C$. Let $\lambda_{1}-\lambda_{2}=\lambda^{\prime}$. When $\beta<\left(S_{2} \lambda^{\prime}-C\right) / S_{2} \lambda^{\prime}$, the auditor performs a complex audit, and vice versa.

a. When $\beta<\left(S_{2} \lambda^{\prime}-C\right) / S_{2} \lambda^{\prime}$, the auditor adopts a complex auditing procedure. In this case, the benefit to a bad official of claiming to be a good official is $E_{1}-E_{2}-E_{3}$. The benefit of admitting being a bad official is $E_{1}-E_{2}$. If $E_{1}-E_{2}-E_{3}<E_{1}-E_{2}$, a bad official admits being a bad official.

b. When $\beta>\left(S_{2} \lambda^{\prime}-C\right) / S_{2} \lambda^{\prime}$, the auditor adopts a simple auditing procedure. In this case, the benefit to a bad official of claiming to be a good official is $E_{1}-E_{2}-E_{3}$. The benefit of admitting being a bad official is $E_{1}-E_{2}$. Because $E_{1}-E_{2}-E_{3}<E_{1}-E_{2}$, a bad official admits being a bad official.

\subsection{Model Analysis Conclusion}

We compare the two scenarios under different conditions. In addition to the presence of a CESS, the whistle-blower's behavioural choice is key to explaining the changes in the game's equilibrium.

i. Local Government officials

According to Scenario 1, when $E_{4}>E_{3} /\left(1-\lambda_{2}\right)$, the local official chooses to lie; that is, a bad official claims to be a good official. In Scenario 2, if the local official suppresses the whistle-blower and $\mu>\left[E_{3}+\left(1-\lambda_{1}\right) V_{4}\right] /[(1-$ $\left.\left.\lambda_{1}\right)\left(E_{4}+V_{4}\right)\right]$, the local official also chooses to lie. If the local official cannot suppress the whistle-blower, he behaves honestly, admitting being a bad official. The first formula can be rearranged to obtain $1-\lambda_{2}>E_{3} / E_{4}$ and the second formula can be rearranged to obtain $1-\lambda_{1}>E_{3} /\left(\mu E_{4}+\right.$ $\left.\mu V_{4}-V_{4}\right)$. Comparing the two formulas shows that the presence of a protection system increases the effects of $\mu$ and $V_{4}$.

If $E_{4}>\mu>V_{4} /\left(E_{4}+V_{4}\right)$ and $\left(1-\lambda_{1}\right) \in\left(E_{3} / E_{4}, E_{3} /\right.$ $\left(\mu E_{4}+\mu V_{4}-V_{4}\right)$, adding the whistle-blower protection mechanism makes the official act honestly. The system protects whistle-blowers from harassment and encourages them to provide useful information to central environmental supervisors and auditors to be used in environmental audits.
Local officials are disciplined to act honestly because the costs of lying are higher than the cost of cooperating.

When $E_{4}>V_{4} /\left(E_{4}+V_{4}\right)>\mu$, we can see that a local official who originally cheated in the audit process is disciplined to act honestly after the introduction of the whistle-blower protection mechanism.

ii. Local resident / whistle-blower

Comparing the analyses of Scenarios 1 and 2 shows that the appointment of central environmental supervisors and the establishment of a whistle-blower protection system changes the behaviour of the whistle-blower due to the addition of the $\mu$ factor.

If other conditions remain unchanged and $\mu<\left(V_{3}+\right.$ $\left.V_{4}\right) /\left(V_{2}+V_{4}\right)$, local officials find it too costly to suppress the whistle-blower due to the presence of the whistle-blower protection mechanism. If $V_{2}$ remains unchanged, the informant finds it beneficial to blow the whistle and report the environmental issue.

iii. Auditors

Local officials are disciplined to act honesty due to the presence of a CESS, which reduces the information asymmetries between the local official and the auditor. It thus reduces audit costs because the auditor can adopt a simple audit procedure instead of a complex one. Due to the appointment of central environmental supervisors, the probability of detecting audit failure increases, increasing $S_{2}$. The increase in $S_{2}$ causes $\left(S_{2} \lambda^{\prime}-C\right) / S_{2} \lambda^{\prime}$ to rise. From the previous analysis, it is known that $\left(S_{2} \lambda^{\prime}-C\right) / S_{2} \lambda^{\prime}$ is the basis for the auditor's audit strategy. The increase in $\left(S_{2} \lambda^{\prime}-C\right) / S_{2} \lambda^{\prime}$ can be interpreted as a change from a simple audit to a complex audit by the auditor.

The above analysis shows that under a CESS, the audit strategy depends on the potential losses anticipated from a possible audit failure detected by other stakeholders. Therefore, we can make the following presumption: with the establishment of the CESC and the introduction of the whistle-blower protection system, government auditors attribute more importance to their reputation and credibility. The tendency to conduct complex audits and the increasing intensity of verification helps auditors reduce the risk of audit failure. The analysis also shows that audit failures have a negative impact on the credibility and reputation of government audits.

\section{Conclusions}

The appointment of central environmental supervisors shows the Chinese government's resolve to environmental protection. Different parties participate and interact with each other in the tripartite game, setting up a cooperative environmental governance system. In this system, local officials are incentivised to fulfil their environmental responsibilities, whistle-blowers are keen to report violations without fear of harassment and auditors provide a quality assurance service with reduced audit failures. The game analysis confirms the impacts of whistle-blowers' behavioural choice on local officials and auditors. They discipline local officials to act honestly and urge auditors to 
adopt detailed audit procedures to reduce audit failures. This ultimately achieves the goal of cooperative environmental governance.

Our analysis has practical political implications. First, the new environmental initiatives have fundamentally changed the environmental supervision system. Environmental supervision is not new in China and has been set up at different levels of government, including the central, provincial, municipal, county and even village levels (China Daily, 2017). Regional supervision centres have been set up as pilot centres since 2002 and spread across China in 2008. However, environmental supervision was viewed as symbolic before the initiative proposed by the $18^{\text {th }}$ Chinese Congress Assembly [36]. Local governments were responsible for supervising themselves; in many cases, the local government acted as a player and referee simultaneously. Obviously, the old supervision system lacked independence. It is not difficult to find examples of local governments collaborating with local enterprises [37]. Local governments need local enterprises to contribute to a higher local GDP for political motives and local enterprises need government assistance to generate profits. Local governments acted as a protective umbrella for polluting enterprises before central supervisors came to visit. Indeed, environmental supervision has become a game of hide-and-seek. The close relationship between local environmental supervision and enterprises meant that environmental audits could not be performed effectively and therefore created potential environmental audit failures. The strengthening of the supervision system by the central government makes local officials account for environmental underperformance. The CESC plays a key role in implementing environmental responsibility and the punishment of thousands of local officials for failure to fulfil their environmental responsibilities shows the public that central supervisors are not toothless regulators ${ }^{4}$. Over the past two years, central environmental protection supervisors have achieved remarkable results in promoting local governments' environmental performance and intensifying rectification efforts.

Second, CESC should be normalised and legalised to incorporate a whistle-blower protection system considering China's unique characteristics. One of the important responsibilities of CESC is to protect whistle-blowers who bypass the local government and come directly to the central supervisors, who are higher in the governmental hierarchy than local officials. CESC is a direct agency established by the State Council. The key central supervisors can be senior officials in the CCDI, the highest internal control institution of the Communist Party. The CCDI is tasked with enforcing internal rules and regulations and combating corruption and malfeasance at all levels of government. CESC and CCDI officials have power over the local environmental department $^{5}$. This enables them to independently protect

Source:

https://www.npr.org/sections/parallels/2017/10/23/559009961/china-shuts-down-t ens-of-thousands-of-factories-in-unprecedented-pollution-crack

${ }^{5}$ Source: http://english.mofcom.gov.cn/column/services.shtml whistle-blowers from local harassment after reporting local environmental issues.

Third, departure audits of outgoing local officials should be linked with public awareness and social media supervision [38]. Increasing public awareness encourages local informants to provide useful information that CESC cannot reach otherwise. Social media can also act as a channel for publishing the latest developments in environmental issues. Government auditors should keep the channel open for local whistle-blowers and increase audit credibility to attract timely information. With the help of whistle-blowers, environmental auditors can access useful information to conduct a more detailed audit.

\section{Acknowledgements}

We acknowledge the financial support of Guangdong provincial natural science foundation of China (Grant Numbers: 2018A030310020), the Guangdong University of Foreign Studies Research Foundation (Grant Numbers: 16QN26 \& 311-GK182020).

\section{References}

[1] http://www.chinadaily.com.cn/china/19thepenationalcongress/ 2017-10/09/ content_33032118.htm

[2] Maung, M., Wilson, C. \& Tang X. B. (2016). Political c onnections and industrial pollution: Evidence based on sta te ownership and environmental levies in china. Journal of Business Ethics, 138 (4): 649-659. https://doi.org/10.100 7/s10551-015-2771-5

[3] Van Rooij, B., Li, N., \& Wang, Q. (2018). Punishing pollu ters: Trends, local practice, influences, and their implication $\mathrm{s}$ for administrative law enforcement in China. China Law and Society Review, 3 (2): 118-176. https://doi.org/10.1163/ 25427466-00302002

[4] Lu, Y., \& Abeysekera, I. (2014). Stakeholders' power, co rporate characteristics, and social and environmental discl osure: Evidence from China. Journal of Cleaner Producti on, 64: 426-436. https://doi.org/10.1016/j.jclepro.2013.10.0 05

[5] Shapiro, J. (2016). China's environmental challenges: John Wiley \& Sons.

[6] Chen, H. S. (2017). Legalization of environmental protect ion supervision system: Location, dilemma and exit. Law Review, 3: 176-187. https://doi.org/10.13415/j.cnki.fxpl.201 7.03.019

[7] Dubey, R., Gunasekaran, A., \& Ali, S.S. (2015). Exploring the relationship between leadership, operational practices, $\mathrm{i}$ nstitutional pressures and environmental performance: A fra mework for green supply chain. International Journal of $\mathrm{Pr}$ oduction Economics, 160: 120-132. https://doi.org/10.1016/j. ijpe.2014.10.001

[8] Malin, M. H. (1983). Protecting the whistle-blower from retaliatory discharge. University of Michigan Journal of $L$ aw Reform. 
[9] Dworkin, T. M., \& Callahan, E. S. (1991). Internal whistleblowing: Protecting the interests of the employee, the organization, and society. American Business Law Journal, 2: 267-308. https://doi.org/10.1111/j.1744-1714.1991.tb00634.x|

[10] Murdock, H. (2003). Protecting the whistle-blower. Intern al Auditor, 60 (6): 8.

[11] Westman, D. P. (2005). The significance of the SarbanesOxley whistle-blower provisions. Labour Lawyer, 2: 141155. https://doi.org/10.2307/40862871

[12] Sawyer, K. R., Johnson, J., \& Holub, M. (2010). The ne cessary illegitimacy of the whistle-blower. Business \& $\mathrm{Pr}$ ofessional Ethics Journal, 29 (1/4): 85-107. https://doi.org/ $10.2139 /$ ssrn.917316

[13] Cordis, A. \& Lambert, E. (2017). Whistle-blower laws an d corporate fraud: Evidence from the United States. Acco unting Forum, 4: 289-299. https://doi.org/10.1016/j.accfor.2 017.10.003.

[14] Lai, C. M., \& Lai, D. L. (2006). Strengthening the syste $\mathrm{m}$ guarantee of citizens reporting rights. Law Science, 7: 14-24.

[15] $\mathrm{Wu}, \mathrm{Y}$. (2013). The private force in public law enforcem ent: Restatement of legal economics of reward and report system. Law Science, 9: 14-23.

[16] Qian, C. \& Chen, J. (2015). Whistle-blower Protection A ct for Chinese drug administration in context of chromiu m-tainted capsule incident. Chinese Pharmaceutical Affair $s$, 6: 563-567. https://doi.org/10.16153/j.10027777.2015.06. 001

[17] Yin, C. Z., Chen, B., Xie, Z., Li, T. \& Li, S. G. (201 5). Improvement of China's reporting reward system on $f$ ood safety referring to western whistle-blower protection act. Journal of Environmental and Occupational Medicin $e$, 6: 597-601. https://doi.org/10.13213/j.cnki.jeom.2015.147 53

[18] Che, P. \& Jin, Y. (2016). On the construction of the wh istle-speaker system in China's food safety supervision: b ased on Articles 115 and 133 of the new Food Safety L aw. Legality Vision, 28: 206.

[19] Luan, F. G. \& Tian, L. Y. (2017) Game analysis of whi stling, company and auditor: Research based on the whist le-blower protection system. Journal of Audit and Econo mics, 1: 38-48.

[20] Zhang, Y. (2017). Rewarding pollution reports highlights environmental protection and governance. Environmental Protection and Circular Economy, 37 (11): 1.

[21] Liu, G. C. (2016). The central environmental protection i nspector plays a supervisory role in investigating and sup ervising people. Environmental Economy, Z3: 21-23.

[22] Ge, C. Z., Weng, Z. X., \& Zhao, X. T. (2016). Environ mental protection inspector: A top instrument for co-respo nsibility of the Party and governmental officials. Chinese Journal of Environmental Management, 1: 57-60. https://d oi.org/10.16868/j.cnki.1674-6252.2016.01.012

[23] Li, X. J. (2017). Experience and suggestion on petition w ork of central environmental inspector. Environmental Pro tection, 13: 62-64. https://doi.org/10.14026/j.cnki.0253-970 5.2017.13.014
[24] Cai, C., \& Bi, M. Y. (2014). Theoretical thinking about accountability audit of natural resource. Auditing Researc $h, 5: 3-9$.

[25] Li, B., \& Yin, H. (2016). The theory and methods of th e natural resources accountability audit of outgoing offici als. Auditing Research, 5: 32-37.

[26] Liu, M. H. \& Sun, J. P. (2016). Research on elements o f accountability audit of natural resources assets for leadi ng carders. Journal of Audit and Economics, 4: 12-20.

[27] Chen, C. B., Geng, X. Y. \& Meng, C. (2016). Thinking based on the practice of accountability audit of natural $\mathrm{r}$ esource in Jiaozhou city. Auditing Research, 4: 10-14.

[28] Wang, Z. Y., Feng, X. M. \& Xu, R. M. (2017). Difficul ties and countermeasures of the departure audit of leadin g cadres' natural resource assets: Taking Fujian Province as an example. Finance Research, 3: 57-61.

[29] Qin, X. L., Liu, J. M. \& Wang, J. Z. (2017). Research on the departure audit of natural resources assets of leading cadres: Based on the practice of Jiangsu province. Friends of Accounting, 20: 97-101.

[30] Zhou, H. B. \& Zhou, Q. (2017). Research on natural res ource asset management based on auditing perspective. $A$ udit Monthly, 1: 18-21. https://doi.org/10.15882/j.cnki.sjyk. 2017.01.006.

[31] Liu, R. B. \& Wang, H. B. (2017). Analysis of audit of outgoing leading officials' natural resources accountability. Auditing Research, 4: 32-38.

[32] Du, X., Wei, J., Zeng, Q. \& Chang, Y. (2018). Do audit ors applaud corporate environmental performance? Eviden ce from China. Journal of Business Ethics, 151 (4): 1049 -1080. https://doi.org/10.1007/s10551-016-3223-6.

[33] Ran, R. (2013). Political incentives and local environment al governance under a 'pressurized system'. Comparative Economic \& Social Systems 3: 111-118.

[34] Li, H. \& Zhou, L. (2005). Political turnover and economi c performance: The incentive role of personnel control in China. Journal of Public Economics, 89 (9-10): 1743-17 62. https://doi.org/10.1016/j.jpubeco.2004.06.009.

[35] Cao, X., Lemmon, M., Pan, X., Qian, M., \& Tian, G. (201 8). Political promotion, CEO incentives, and the relationshi $\mathrm{p}$ between pay and performance. Management Science. http s://doi.org/10.1287/mnsc.2017.2966.

[36] Lu, Y., \& Abeysekera, I. (2017). What do stakeholders c are about? Investigating corporate social and environment al disclosure in China. Journal of Business Ethics, 144 (1): 169-184. https://doi.org/10.1007/s10551-015-2844-5

[37] Huang, F. (2017). Research on collusion of government a nd enterprise in environmental regulation and its preventi ve mechanism: Jiangsu University.

[38] Schaltegger, S., \& Wagner, M. (2017). Managing the busin ess case for sustainability: The integration of social, enviro nmental and economic performance: Routledge. 